\title{
Secondary electrospray ionization proceeds via gas-phase chemical ionization
}

Cite this: Anal. Methods, 2017, 9, 5052

\author{
Alberto Tejero Rioseras, (DD abc Martin Thomas Gaugga and Pablo Martinez-Lozano \\ Sinues (ID *ad
}

Our main goal was to gain further insights into the mechanism by which gas-phase analytes are ionized by interaction with plumes of electrospray solvents. We exposed target vapors to electrosprays of either water or deuterated water and mass analyzed them. Regardless of the solvent used, the analytes were detected in protonated form. In contrast, when the ionization chamber was humidified with deuterated water, the target vapors were detected in deuterated form. These observations suggest that either there is no interaction between analytes and electrospray charged droplets, or if there is any, a subsequent gas-phase ionmolecule reaction governs the process. Implications in practical examples such as breath analysis are discussed.

Received 30th April 2017

Accepted 20th June 2017

DOI: 10.1039/c7ay01121k

rsc.li/methods
While it is generally accepted that SESI coupled to modern atmospheric pressure mass spectrometry is a sensitive method to detect gases at trace concentrations in real-time, the lack of full understanding of the SESI mechanism prevents making rational choices for the optimal parameters. In addition, with the advent of several ambient mass spectrometry techniques with overlapping features, fundamental aspects of such techniques have been blurred or confused. ${ }^{25}$ Our goal in this study was to further previous work on the mechanism by which strictly vapor species are ionized in contact with electrospray plumes of pure solvents..$^{26,27}$

\section{Methods}

\section{SESI-MS}

A commercially available SESI source (SEADM, Spain) was used in all experiments. ${ }^{28}$ It was interfaced with an Orbitrap mass spectrometer (Thermo) and on one occasion (data shown in Fig. 5) with a TripleTOF 5600+ (Sciex).

The SESI was operated in the nanoliter range $(\sim 100 \mathrm{~nL}$ $\min ^{-1}$ ). We flushed the electrospray region with compressed air at a flow rate of $1 \mathrm{~L} \mathrm{~min}^{-1}$. Compressed air contained around $5 \%$ relative humidity. Between the mass flow controller (Bronkhorst) and the ionization chamber, we placed a threeneck flask with rubber stoppers. Different liquids were injected into the flask to seed the carrier air with their corresponding vapors. Injected ambient vapors included water $\left(\mathrm{H}_{2} \mathrm{O}\right)$, deuterated water $\left(\mathrm{D}_{2} \mathrm{O}\right)$, ethanol $(\mathrm{EtOH})$ and deuterated ethanol (EtOD). Relative humidity within the flask was recorded with a sensor (Alborn Almemo 2590A).

\section{Breath analysis}

SESI-MS breath analysis was accomplished by exhaling through the sampling tube of the ion source at a constant exhalation pressure of 10 mbar, as measured by a digital manometer. 
The study was approved by the local ethical committee (EK 2012-N-49) and the subject gave written informed consent to participate.

\section{Results and discussion}

\section{Deuterated spray solvent}

Two (simplified) ionization scenarios are plausible in SESI: (i) the neutral species dissolve into the charged electrospray droplets to eventually be re-ejected in ionized form into the gasphase; (ii) electrospray droplets eject primary reactant ions that undergo an ion-molecule reaction with neutral species. Obviously, both mechanisms lead to very different scenarios to optimize the ionization efficiency. For the former mechanism, solubility of the analyte on the charging spray solvent would be crucial to maximize ionization efficiency. In the latter mechanistic scenario, analyte detection would be ultimately governed by thermochemistry.

In order to determine which of the two potential scenarios apply in SESI we exposed neutral vapors to electrosprays of water and deuterated water. The exchange of hydrogen/ deuterium has provided very valuable mechanistic insights since the initial developments of chemical ionization/massspectrometry. ${ }^{29-32}$ We hypothesized that, if the neutral vapors interact with the electrospray charged droplets to be re-emitted as gas-phase ions, they should be detected as $[\mathrm{M}+\mathrm{D}]^{+}$ions.

Typical SESI-MS spectra has a rich chemical background in the range 50-500 $\mathrm{Da}^{33,34}$ For example, volatile polydimethylcyclosiloxanes in ambient laboratory air are wellknown interfering species in mass spectrometry. ${ }^{35,36}$ Similarly, phthalates have also been reported to off-gas from vacuum orings. ${ }^{37}$ Thus, we took advantage of the presence of these ubiquitous gas-phase contaminants to gain insights into how nano-electrosprays of solvent eventually lead to the ionization of such species. Fig. 1 shows the mass spectra resulting of flushing the electrospray chamber with compressed air and using as spray solvent either $0.15 \%$ formic acid in $\mathrm{H}_{2} \mathrm{O}$ (a) or $0.15 \%$ deuterated acetic acid (i.e. $\mathrm{CD}_{3}$-COOD) in $\mathrm{D}_{2} \mathrm{O}(\mathrm{b})$. The

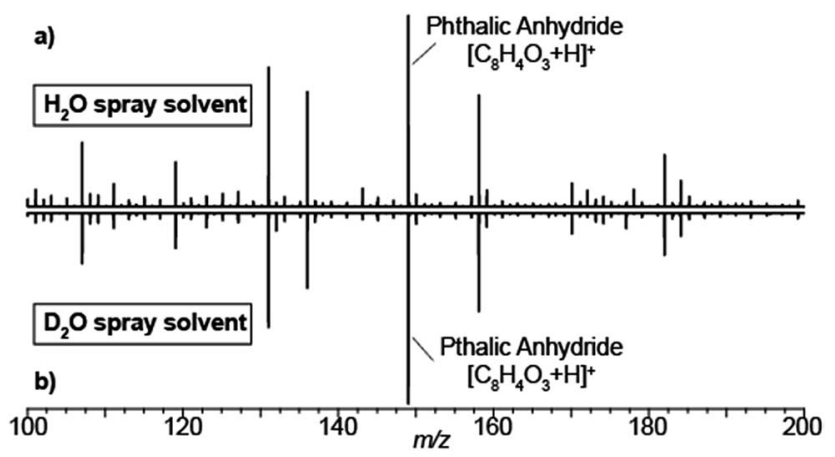

Fig. 1 SESI mass spectra are independent of whether electrospray solvent is water or deuterated water. SESI chemical noise mass spectra with different electrospray solutions: (a) $0.15 \%$ formic acid in $\mathrm{H}_{2} \mathrm{O}$; (b) $0.15 \%$ deuterated acetic in $\mathrm{D}_{2} \mathrm{O}$. In both cases, the analytes were detected in protonated form. For reference, the dominating peak of phthalic anhydride is labelled. resulting spectra are identical, including the known polysiloxanes and phthalates volatile species. Thus, regardless of the use of protonated or deuterated solvents, all species were detected in protonated form. This suggests that, even if the gasphase species interact with the droplets to acquire a deuterium, eventually they exchange the deuterium with a proton in the gas-phase. In this case, with ambient water vapor, as the carrier gas contained $\sim 5 \%$ of relative humidity.

\section{Doping carrier gas with deuterated vapors}

The data shown in Fig. 1b strongly suggest that a gas-phase proton reaction takes place in SESI. To further confirm this hypothesis, we humidified the carrier air with either water or deuterated water. As a result of humidifying with deuterated water, the entire chemical background mass spectrum shifted by 1 Da. Fig. 2 shows a zoomed view of the mass spectrum in the region of one representative example of a phthalate $\left(\mathrm{C}_{16} \mathrm{H}_{22} \mathrm{O}_{4}\right)$ and a polysiloxane $\left(\mathrm{C}_{12} \mathrm{H}_{36} \mathrm{Si}_{6} \mathrm{O}_{6}\right)$ with $\mathrm{H}_{2} \mathrm{O}$-humidified air (bottom) and $\mathrm{D}_{2} \mathrm{O}$-humidified air (top). The fact that these species deuterate when the air is seeded with deuterated water vapor, but not when deuterated water is used in the spray solvent, strongly indicates that gas-phase ion chemistry plays a critical role in SESI, if not the only one.

Further insight was gained by seeding the carrier gas with ethanol instead of water. Ethanol has a greater gas-phase proton affinity than water $\left(776.4\right.$ vs. $\left.691 \mathrm{~kJ} \mathrm{~mol}^{-1}\right)$. Thus, it would be expected that, if SESI is governed by thermochemistry of the water and ethanol proton transfer reaction, it would be detected in the presence of the former but not the latter. Fig. 3a and $\mathrm{b}$ illustrate the behavior of another representative compound (benzothiazole; $\mathrm{C}_{7} \mathrm{H}_{5} \mathrm{NS}$ ). ${ }^{38}$ Fig. 3a shows the $[\mathrm{M}+\mathrm{D}]^{+} /[\mathrm{M}+\mathrm{H}]^{+}$ ratio before and after humidifying with $\mathrm{D}_{2} \mathrm{O}$. Clearly, at the time point of $\mathrm{D}_{2} \mathrm{O}$ injection, the protonated species decays, while simultaneously the deuterated adduct rises. Fig. $3 \mathrm{~b}$ shows the result of a similar experiment, but instead of $\mathrm{D}_{2} \mathrm{O}$, we seeded the SESI chamber with vapors of EtOD. Likewise, the deuterated

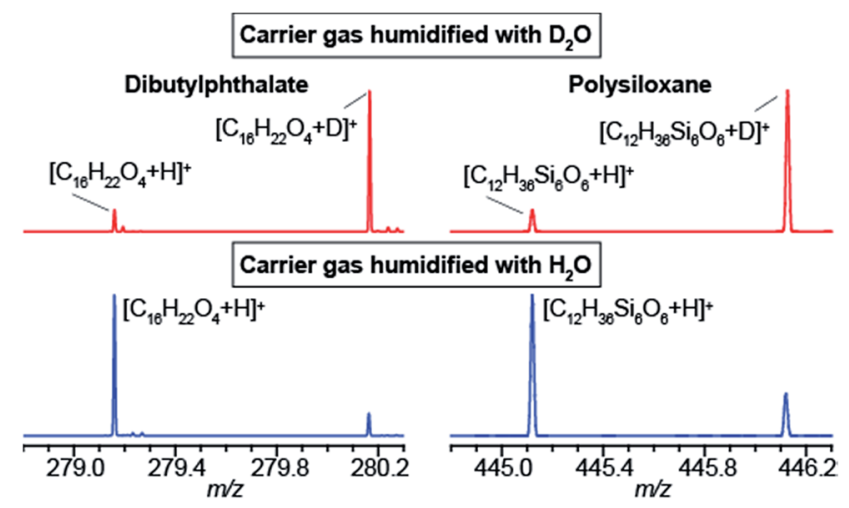

Fig. 2 Humidifiying the carrier air with deuterated water leads to deuterated ions in SESI-MS. Electrospray solvent was $0.15 \%$ formic acid in $\mathrm{H}_{2} \mathrm{O}$. Mass spectra of dibutylphthalate (left) and a polysiloxane (right). As expected, humidifying with $\mathrm{H}_{2} \mathrm{O}$ leads to protonated species (i.e. $[\mathrm{M}+\mathrm{H}]^{+}$; bottom) and humidifying with $\mathrm{D}_{2} \mathrm{O}$ leads to deuterated species (i.e. $[\mathrm{M}+\mathrm{D}]^{+}$; top). 

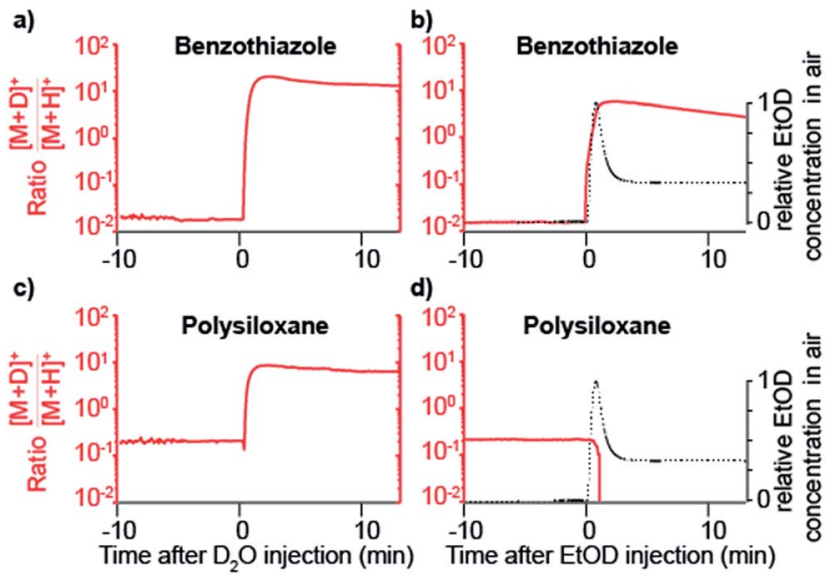

d)

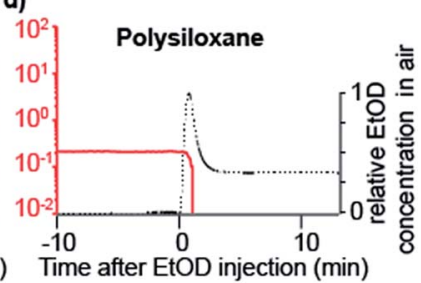

Fig. 3 Gas-phase proton affinity of seeding vapors have an effect in SESI analyte detection. Benzothiazole deuterates after adding vapors of $\mathrm{D}_{2} \mathrm{O}(\mathrm{a})$ and EtOD (b) in the carrier gas. In contrast, the deuterated form of the polysiloxane was detected with $\mathrm{D}_{2} \mathrm{O}$ (c), but depleted upon exposure to EtOD vapors (d). Relative concentrations of EtOD in the carrier gas are shown for reference.

adduct rose sharply in parallel with the relative EtOD concentration in air, suggesting a direct correlation between EtOD levels and $\left[\mathrm{C}_{7} \mathrm{H}_{4} \mathrm{NS}+\mathrm{D}\right]^{+}$signal intensity. In contrast, the polysiloxane experienced the same response upon exposure to $\mathrm{D}_{2} \mathrm{O}$ vapors (Fig. 3c), but the signal dropped abruptly to 0 after introducing EtOD (Fig. 3d). Hence, Fig. 3c and d suggests that the polysiloxane has a gas-phase proton affinity greater than water, but lower than ethanol.

To confirm that gas-phase thermochemistry ultimately dictates which analytes are detectable by SESI, we chose 2,2,2trifluoroethanol as target analyte vapor. This particular compound has gas-phase proton affinity of $700.2 \mathrm{~kJ} \mathrm{~mol}^{-1}, 39$ which is in between that of water and ethanol. As expected, this compound was detected as deuterated ion upon doping the carrier gas with $\mathrm{D}_{2} \mathrm{O}$, but not when EtOD was used.

Fig. 4a shows how the $[\mathrm{M}+\mathrm{D}]^{+} /[\mathrm{M}+\mathrm{H}]^{+}$ratio rises sharply immediately after injecting $\mathrm{D}_{2} \mathrm{O}$. For reference, relative humidity levels, as measured with the sensor, are overlaid. When the same experiment is performed but instead of $\mathrm{D}_{2} \mathrm{O}$, EtOD is injected in the carrier gas, 2,2,2-trifluoroethanol is no longer detected (Fig. 4b).

We have just shown compelling evidence indicating that SESI leads to protonated species, even if the spray solvent is deuterated, as long as some water vapor is present in the carrier gas of the sample (in our case $\sim 5 \%$ relative humidity). This directly leads to a gas-phase chemical ionization scenario, at least in the final step of the process. Our hypothesis to explain this observation is that, initially, $\left[\left(\mathrm{D}_{2} \mathrm{O}\right)_{n}+\mathrm{D}\right]^{+}$clusters are ejected from the electrospray droplets by ion evaporation..$^{\mathbf{4 0 - 4 4}}$ These primary ions rapidly exchange deuterium by protons with ambient water, which is in excess in ambient air, leading to eventually dominating $\left[\left(\mathrm{H}_{2} \mathrm{O}\right)_{n}+\mathrm{H}\right]^{+}$clusters. These water clusters would then undergo a proton transfer reaction with neutral vapor species, provided the reaction is thermodynamically favorable. Of course, kinetically-controlled reactions are
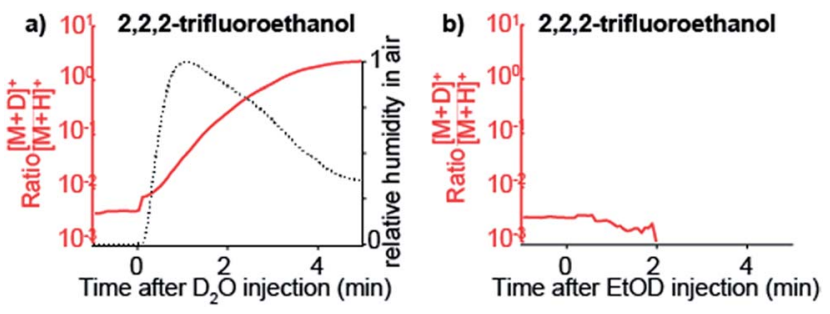

Fig. 4 SESI selectivity towards target vapors is governed by the proton affinity of the dopant seeded in the carrier gas. Response of 2,2,2trifluoroethanol vapors in the presence of $\mathrm{D}_{2} \mathrm{O}(\mathrm{a})$ and EtOD (b) in the carrier gas. When $\mathrm{D}_{2} \mathrm{O}$ is introduced in the system the protonated ion declines in favor of the deuterated species (a). In contrast, when EtOD is introduced in excess in the carrier gas the signal of $\left[\mathrm{C}_{2} \mathrm{H}_{3} \mathrm{~F}_{3} \mathrm{O}+\mathrm{H}\right]^{+}$ drops quickly to zero, but the $\left[\mathrm{C}_{2} \mathrm{H}_{3} \mathrm{~F}_{3} \mathrm{O}+\mathrm{D}\right]^{+}$ion is not formed (b). This is explained by the fact that the gas-phase proton affinity of 2,2,2trifluoroethanol is greater than water, but smaller than ethanol.

also conceivable for slow proton transfer, which indeed is known to be the case for many reactions in chemical ionization. ${ }^{44-46}$ For example, under our particular experimental conditions in Fig. 1b, we formed the electrospray by infusing $\mathrm{D}_{2} \mathrm{O}$ at $\sim 100 \mathrm{~nL} \mathrm{~min}{ }^{-1}$. If we assume that all $\mathrm{D}_{2} \mathrm{O}$ is immediately vaporized, and considering that the ambient air flushing the SESI chamber at $1 \mathrm{~L} \mathrm{~min}^{-1}$ contained $5 \%$ relative humidity, the expected ratio $\mathrm{H}_{2} \mathrm{O} / \mathrm{D}_{2} \mathrm{O}$ in the ionization chamber is in the order of 10. This excess of $\mathrm{H}_{2} \mathrm{O}$ would then shift the equilibrium of reactant ions from $\left[\left(\mathrm{D}_{2} \mathrm{O}\right)_{n}+\mathrm{D}\right]^{+}$towards $\left[\left(\mathrm{H}_{2} \mathrm{O}\right)_{n}+\mathrm{H}\right]^{+}$. This hypothesis is supported by the data shown in Fig. 5. It shows a SESI mass spectrum using water-formic acid as electrospray solvent and the carrier gas bathing the SESI chamber humidified with a 50/50 mixture of $\mathrm{H}_{2} \mathrm{O}$ and $\mathrm{D}_{2} \mathrm{O}$. It shows two binomial distributions for the water trimer and tetramer with all possible combinations of hydrogen and deuterium atoms.

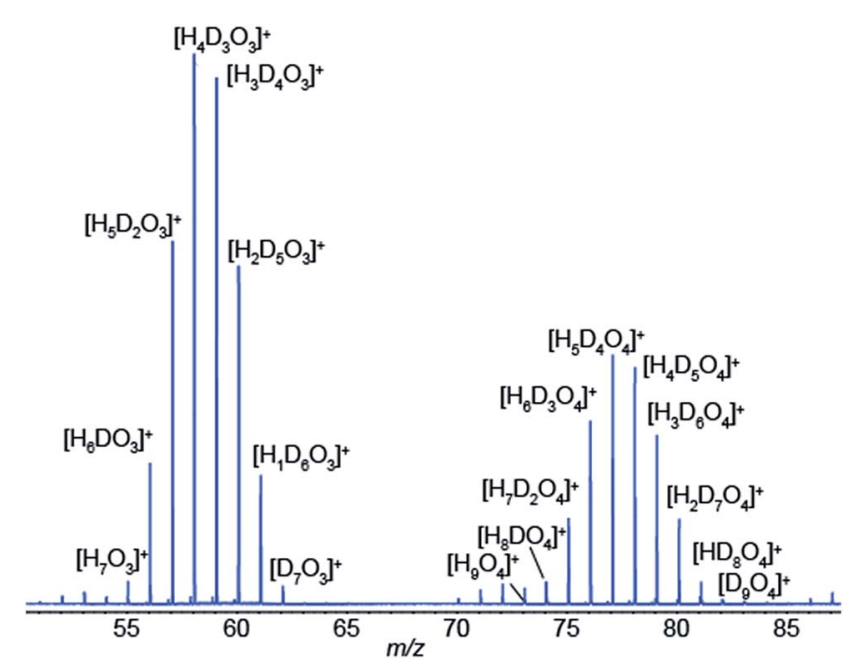

Fig. 5 SESI gas-phase reactant ions in the presence of humidity are water clusters. Example of an electrospray of $0.15 \%$ formic acid in water flushed with a $50 / 50$ mixture of $\mathrm{H}_{2} \mathrm{O} / \mathrm{D}_{2} \mathrm{O}$ vapors, leading to all possible $\left[\mathrm{H}_{x} \mathrm{D}_{y} \mathrm{O}_{3}\right]^{+}(x+y=7)$ combinations for the trimer (left-handside) and $\left[\mathrm{H}_{x} \mathrm{D}_{y} \mathrm{O}_{4}\right]^{+}(x+y=9)$ for the tetramer (right-hand-side). 
Warnings about the importance of gas-phase ion chemistry in the standard electrospray process have been given in the literature. ${ }^{47}$ For example, Enke and co-workers convincingly showed that analytes present in solution are very likely to be ultimately depleted in the gas phase by the presence of molecules that are stronger gas-phase bases, resulting in ion suppression. ${ }^{39}$ Our data support this view, and extend it to SESI. Hence, we have advocated that one should be cautious when distinguishing the real-time analysis of gas- vs. condensedphase analytes with sprays of pure solvent. ${ }^{26}$ The main reason is that a number of studies have suggested that for samples delivered in aerosol form (i.e. extractive electrospray ionization), solubility of the analytes and interaction with the charging spray solvent is the limiting factor to be considered. ${ }^{48,49} \mathrm{We}$ argue here that, in the case of vapor samples (i.e. secondary electrospray ionization), gas-phase ion chemistry considerations are ultimately governing the detection of such analytes. For this reason, we claim that water electrosprays operated in the cone-jet mode ${ }^{50}$ are preferred in positive ion mode SESI over widely used $\mathrm{H}_{2} \mathrm{O} / \mathrm{MeOH}$ mixtures, as $\mathrm{MeOH}$ will probably deplete species detectable otherwise.

\section{Breath analysis}

The analysis of exhaled metabolites in breath is an attractive approach to monitor health status and therapeutic intervention. ${ }^{51}$ Selected ion flow tube mass spectrometry (SIFT-MS) ${ }^{52}$ and proton transfer reaction mass spectrometry (PTR-MS) ${ }^{53}$ are two well established methods for real-time detection of volatiles in breath. One of the main strengths of SIFT-MS is its capability to provide absolute quantifications of trace gases in the partsper-million to parts-per-billion range.$^{54}$ PTR-MS provides semiquantitative information with limits of detection down to parts-per-trillion. Exhaling onto an electrospray plume in front of an atmospheric pressure ionization MS is another highly efficient way to perform such analyses. A wide range of species have been reported using this method; however chemical identification and absolute quantification of the species detected remain a challenge. Given that, low-volatility species such as urea have been detected using this approach, ${ }^{55,56}$ there has been some debate regarding whether the metabolites detected in breath following this approach come in aerosol form or simply the method is sensitive enough to detect low-volatility vapors. ${ }^{17,55,56}$ The debate is of importance because aerosols and volatiles have different physiological origins and therefore offer different diagnostic opportunities. Aerosols in breath are thought to be generated by the turbulence-induced aerosolization mechanism of the fluid film in the respiratory tract. ${ }^{57}$ This leads to a high variability on particle size distribution and number depending on the inhalation and exhalation maneuvers $^{57}$ and hence difficulties in reproducibility. In contrast, the origin of gas-phase species is predominantly blood borne and therefore enable monitoring different metabolic processes. ${ }^{58}$ We argue that breath analysis by SESI-MS detects volatile and non-volatile gas-phase species following that: (i) truly nonvolatile macromolecules such as cytokines have been reported in exhaled breath condensate,,$^{59}$ but are not detectable by SESI-

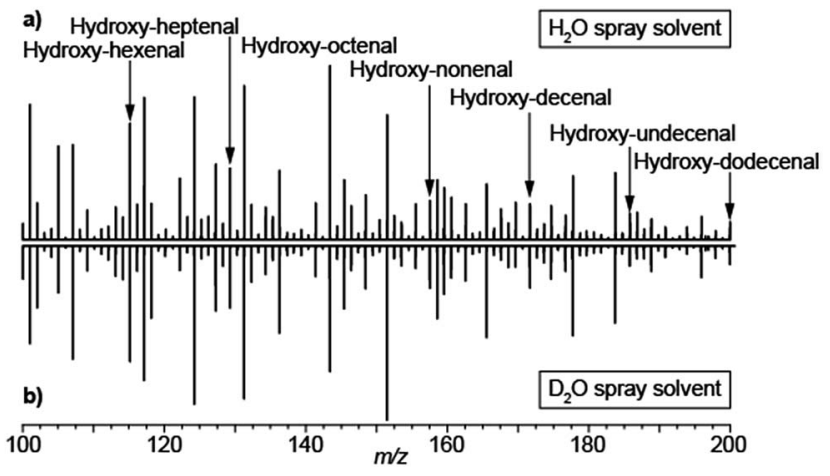

Fig. 6 Breath metabolites are ultimately protonated via gas-phase ion-molecule reactions in SESI: (a) breath mass spectrum using $0.15 \%$ formic acid in water; (b) breath mass spectrum using $0.15 \%$ acetic acid- $d_{4}$ in heavy water. Breath metabolites were detected in protonated form regardless of the solvent used to generate the electrospray. For reference, a series of hydroxy-alkenals previously identified by García-Gómez ${ }^{63}$ are indicated.

MS; (ii) exhaling through a particle filter leads to essentially the same mass spectrum as without such a filter; ${ }^{55}$ (iii) analytical ${ }^{27}$ and numerical ${ }^{28}$ models capture experimental observations with reasonable accuracy in systematic mechanistic studies ${ }^{26}$ and (iv) we have shown how small amounts of injected drugs in mice can be detected in breath shortly afterwards and correlate with plasma levels. ${ }^{60,61}$ For example, ketamine and its main metabolites, which have molecular weights in the range of 250 $\mathrm{Da}$ and a relatively low estimated vapor pressure in the order of $8.5 \times 10^{-5} \mathrm{mmHg}$ at $25^{\circ} \mathrm{C}$ (SPARC online calculator). ${ }^{62}$

To further shed light on this mechanistic issue we performed SESI-MS breath analysis using $\mathrm{H}_{2} \mathrm{O}$ and $\mathrm{D}_{2} \mathrm{O}$ as spray solvents. Aerosolized samples have been shown to interact in the liquidphase between charged electrospray droplets and neutral sample aerosols..$^{48}$ Hence we hypothesized that, if the detected compounds would come in aerosol form, they would necessarily pick up a deuterium from the $\mathrm{D}_{2} \mathrm{O}$ charged droplets and a proton from $\mathrm{H}_{2} \mathrm{O}$ sprays. Fig. 6 shows the breath mass spectrum of one subject exhaling onto a spray of $0.15 \%$ formic acid in water (a) and $0.15 \%$ acetic acid- $\mathrm{d}_{4}$ in $\mathrm{D}_{2} \mathrm{O}$ (b). In both cases, the spectra were identical, with the vast majority of the species detected in protonated form. This may also explain the noted sensitivity enhancement of SESI in the presence of water vapor in breath. ${ }^{55,64}$ Admittedly, these data cannot completely exclude the possibility of exhaled aerosols and vapors dissolving in the charged droplets, generation of $[\mathrm{M}+\mathrm{D}]^{+}$gas-phase ions and subsequently exchanging $\mathrm{H}-\mathrm{D}$ in the gas phase with ubiquitous water vapor. However, it clearly shows that, even if this is the case, gas-phase ion chemistry ultimately plays a critical role in the ionization of breath metabolites.

\section{Conclusions}

We conclude that (i) neutral vapors carried in an air stream (5\% relative humidity) and exposed to an electrospray of deuterated water leads to protonated ions; (ii) inversely, neutral vapors carried in an air stream seeded with deuterated solvents (e.g. 
$\mathrm{D}_{2} \mathrm{O}$ ), and exposed to an electrospray of water leads to deuterated ions; (iii) gas-phase proton affinity of the target analytes plays a crucial role in whether or not they are finally detected in SESI; (iv) breath metabolites are detected in protonated form regardless of whether the solvent used is $\mathrm{H}_{2} \mathrm{O}$ or $\mathrm{D}_{2} \mathrm{O}$. These observations lead us to conclude that, in the final stage of SESI, gas-phase ion-molecule reactions govern the mechanism by which electrosprays ionize vapor species.

\section{Acknowledgements}

We are thankful to Prof. Renato Zenobi for hosting the ACID project at ETH Zurich and for critically reading this manuscript. We gratefully thank Dr Juan Zhang (Novartis AG) for the donation of the LTQ Orbitrap instrument used in this study and Prof. Malcolm Kohler (University Hospital Zurich) for giving access to the Sciex mass spectrometer. The research leading to these results has received funding from the European Community's Seventh Framework Programme (FP7-2013-IAPP) within the project "Analytical Chemistry Instrumentation Development" (609691). This work is dedicated to Prof. John B. Fenn (1917-2010) on the occasion of the centennial celebration of his birth.

\section{References}

1 M. E. Monge, G. A. Harris, P. Dwivedi and F. M. Fernández, Chem. Rev., 2013, 113, 2269-2308.

2 M. Z. Huang, S. C. Cheng, Y. T. Cho and J. Shiea, Anal. Chim. Acta, 2011, 702, 1-15.

3 F. M. Benoit, W. R. Davidson, A. M. Lovett, S. Nacson and A. Ngo, Int. Arch. Occup. Environ. Health, 1985, 55, 113-120.

4 F. M. Benoit, W. R. Davidson, A. M. Lovett, S. Nacson and A. Ngo, Anal. Chem., 1983, 55, 805-807.

5 B. A. Thomson, W. R. Davidson and A. M. Lovett, Environ. Health Perspect., 1980, 36, 77-84.

6 A. M. Lovett, N. M. Reid, J. A. Buckley, J. B. French and D. M. Cameron, Biomed. Mass Spectrom., 1979, 6, 91-97.

7 D. A. Lane and B. A. Thomson, J. Air Pollut. Control Assoc., 1981, 31, 122-127.

8 J. B. Fenn, M. Mann, C. K. Meng, S. F. Wong and C. M. Whitehouse, Science, 1989, 246, 64-71.

9 S. Fuerstenau, P. Kiselev and J. B. Fenn, ESIMS in the Analysis of Trace Species in Gases, Dallas (TX), 1999.

10 S. Fuerstenau, PhD thesis, Yale University, 1994.

11 C. M. Whitehouse, F. Levin, C. K. Meng and J. B. Fenn, Further Adventures with an Electrospray Ion Source, Cincinnati, OH, 1986.

12 Y. H. Chen, H. H. Hill and D. P. Wittmer, J. Microcolumn Sep., 1994, 6, 515-524.

13 C.-M. Hong, F.-C. Tsai and J. Shiea, Anal. Chem., 2000, 72, 1175-1178.

14 C. Y. Lee and J. Shiea, Anal. Chem., 1998, 70, 2757-2761.

15 M. Tam and H. H. Hill, Anal. Chem., 2004, 76, 2741-2747.

16 C. Wu, W. F. Siems and H. H. Hill, Anal. Chem., 2000, 72, 396-403.
17 X. Li, L. Huang, H. Zhu and Z. Zhou, Rapid Commun. Mass Spectrom., 2017, 31, 301-308.

18 J. C. Wolf, M. Schaer, P. Siegenthaler and R. Zenobi, Anal. Chem., 2015, 87, 723-729.

19 M. J. Aernecke, T. Mendum, G. Geurtsen, A. Ostrinskaya and R. R. Kunz, J. Phys. Chem. A, 2015, 119, 11514-11522.

20 J. C. Reynolds, M. A. Jimoh, C. Guallar-Hoyas, C. S. Creaser, S. Siddiqui and C. L. P. Thomas, J. Breath Res., 2014, 8, 037105.

21 L. Meier, C. Berchtold, S. Schmid and R. Zenobi, J. Mass Spectrom., 2012, 47, 1571-1575.

22 L. A. Dillon, V. N. Stone, L. A. Croasdell, P. R. Fielden, N. J. Goddard and C. L. Paul Thomas, Analyst, 2010, 135, 306-314.

23 J. Zhu, H. D. Bean, Y. M. Kuo and J. E. Hill, J. Clin. Microbiol., 2010, 48, 4426-4431.

24 N. Brenner, M. Haapala, K. Vuorensola and R. Kostiainen, Anal. Chem., 2008, 80, 8334-8339.

25 A. J. Ingram, C. L. Boeser and R. N. Zare, Chem. Sci., 2016, 7, 39-55.

26 P. Martinez-Lozano Sinues, E. Criado and G. Vidal, Int. J. Mass Spectrom., 2012, 313, 21-29.

27 J. F. de la Mora, Int. J. Mass Spectrom., 2011, 300, 182-193.

28 C. Barrios-Collado, G. Vidal-de-Miguel and P. MartinezLozano Sinues, Sens. Actuators, B, 2016, 223, 217-225.

29 D. F. Hunt, C. N. Mcewen and R. A. Upham, Tetrahedron Lett., 1971, 4539-4542.

30 D. F. Hunt, C. N. Mcewen and R. A. Upham, Anal. Chem., 1972, 44, 1292-1294.

31 W. Blum, E. Schlumpf, J. G. Liehr and W. J. Richter, Tetrahedron Lett., 1976, 17, 565-568.

32 A. K. Meher and Y. C. Chen, Anal. Chim. Acta, 2017, 966, 4146.

33 B. O. Keller, J. Sui, A. B. Young and R. M. Whittal, Anal. Chim. Acta, 2008, 627, 71-81.

34 X. Guo, A. P. Bruins and T. R. Covey, Rapid Commun. Mass Spectrom., 2006, 20, 3145-3150.

35 A. Schlosser and R. Volkmer-Engert, J. Mass Spectrom., 2003, 38, 523-525.

36 J. C. Reynolds, G. J. Blackburn, C. Guallar-Hoyas, V. H. Moll, V. Bocos-Bintintan, G. Kaur-Atwal, M. D. Howdle, E. L. Harry, L. J. Brown, C. S. Creaser and C. L. P. Thomas, Anal. Chem., 2010, 82, 2139-2144.

37 K. M. Verge and G. R. Agnes, J. Am. Soc. Mass Spectrom., 2002, 13, 901-905.

38 D. Garcia-Gomez, L. Bregy, Y. Nussbaumer-Ochsner, T. Gaisl, M. Kohler and R. Zenobi, Environ. Sci. Technol., 2015, 49, 12519-12524.

39 M. a. H. Amad, N. B. Cech, G. S. Jackson and C. G. Enke, J. Mass Spectrom., 2000, 35, 784-789.

40 J. V. Iribarne, P. J. Dziedzic and B. A. Thomson, Int. J. Mass Spectrom. Ion Phys., 1983, 50, 331-347.

41 B. A. Thomson and J. V. Iribarne, J. Chem. Phys., 1979, 71, 4451-4463.

42 J. V. Iribarne and B. A. Thomson, J. Chem. Phys., 1976, 64, 2287-2294. 
43 V. Znamenskiy, I. Marginean and A. Vertes, J. Phys. Chem. A, 2003, 107, 7406-7412.

44 J. Sunner, G. Nicol and P. Kebarle, Anal. Chem., 1988, 60, 1300-1307.

45 J. Sunner, M. G. Ikonomou and P. Kebarle, Anal. Chem., 1988, 60, 1308-1313.

46 G. Nicol, J. Sunner and P. Kebarle, Int. J. Mass Spectrom. Ion Processes, 1988, 84, 135-155.

47 P. Kebarle and U. H. Verkerk, Mass Spectrom. Rev., 2009, 28, 898-917.

48 W. S. Law, R. Wang, B. Hu, C. Berchtold, L. Meier, H. W. Chen and R. Zenobi, Anal. Chem., 2010, 82, 4494-4500.

49 R. Wang, A. Gröhn, L. Zhu, R. Dietiker, K. Wegner, D. Günther and R. Zenobi, Anal. Bioanal. Chem., 2011, 402, 1-11.

50 J. López-Herrera, A. Barrero, A. Boucard, I. Loscertales and M. Márquez, J. Am. Soc. Mass Spectrom., 2004, 15, 253-259.

51 J. D. Beauchamp and J. D. Pleil, in Biomarker Validation, Wiley-VCH Verlag GmbH \& Co. KGaA, 2015, pp. 75-93, DOI: $10.1002 / 9783527680658 . c h 5$.

52 P. Španěl and D. Smith, in Volatile Biomarkers, ed. A. Amann and D. Smith, Elsevier, Boston, 2013, pp. 48-76, DOI: 10.1016/B978-0-44-462613-4.00004-0.

53 R. S. Blake, P. S. Monks and A. M. Ellis, Chem. Rev., 2009, 109, 861-896.

54 D. Smith, P. Španěl, J. Herbig and J. Beauchamp, J. Breath Res., 2014, 8, 027101.

55 P. Martínez-Lozano and J. Fernández de la Mora, Int. J. Mass Spectrom., 2007, 265, 68-72.

56 H. Chen, A. Wortmann, W. Zhang and R. Zenobi, Angew. Chem., Int. Ed., 2007, 46, 580-583.
57 G. R. Johnson and L. Morawska, J. Aerosol Med. Pulm. Drug Delivery, 2009, 22, 229-237.

58 W. Miekisch, J. K. Schubert and G. F. E. Noeldge-Schomburg, Clin. Chim. Acta, 2004, 347, 25-39.

59 I. Horváth, J. Hunt, P. J. Barnes, K. Alving, A. Antczak, E. Baraldi, G. Becher, W. J. C. van Beurden, M. Corradi, R. Dekhuijzen, R. A. Dweik, T. Dwyer, R. Effros, S. Erzurum, B. Gaston, C. Gessner, A. Greening, L. P. Ho, J. M. Hohlfeld, Q. Jöbsis, D. Laskowski, S. Loukides, D. Marlin, P. Montuschi, A. C. Olin, A. E. Redington, P. Reinhold, E. L. J. van Rensen, I. Rubinstein, P. Silkoff, K. Toren, G. Vass, C. Vogelberg, H. Wirtz, B. Balint, A. Blomberg, J. Freels, M. Goldman, J. Hunt, S. A. Kharitonov, F. Kelly, C. Lehmann, A. Lindstrom, R. Robbins, M. Rothe, H. J. Smith, W. R. Steinhaeusser, W. G. Teague and J. Vaughan, Eur. Respir. J., 2005, 26, 523548.

60 X. Li, P. Martinez-Lozano Sinues, R. Dallmann, L. Bregy, M. Hollmen, S. Proulx, S. A. Brown, M. Detmar, M. Kohler and R. Zenobi, Angew. Chem., Int. Ed., 2015, 54, 7815-7818.

61 P. Martinez-Lozano Sinues, M. Kohler, S. A. Brown, R. Zenobi and R. Dallmann, Chem. Commun., 2017, 53, 2264-2267.

62 H. P. H. Arp, S. T. J. Droge, S. Endo, W. Giger, K.-U. Goss, S. B. Hawthorne, S. A. Mabury, P. Mayer, M. S. McLachlan, J. F. Pankow, R. P. Schwarzenbach, F. Wania and B. Xing, Environ. Sci. Technol., 2010, 44, 4400-4401.

63 D. García-Gómez, P. Martínez-Lozano Sinues, C. BarriosCollado, G. Vidal-De-Miguel, M. Gaugg and R. Zenobi, Anal. Chem., 2015, 87, 3087-3093.

64 P. Martinez-Lozano and J. Fernandez de la Mora, Anal. Chem., 2008, 80, 8210-8215. 